\title{
تصميم المواد التعليمية في درس اللغة العربية لتنمية مهارة القراءة
}

\author{
Aqif Khilmia \\ Universitas Darussalam Gontor \\ aihilmia1995@gmail.com
}

\begin{abstract}
The University of Darussalam Gontor is a university that pays attention to learning Arabic. This is by the curriculum in each study program. As the founder stated that University must be a university that consistently teaches the language of the Qur`an, all students must master Arabic. However, the Islamic Economics study program does not yet have Arabic language teaching materials that have a bad impact on lecturers or students in the teaching and learning process. So, the researchers tried to compile Arabic language teaching materials specifically for students of Islamic Economics study programs at the University of Darussalam Gontor.

The formulation of the research problem is "What the characteristics of Arabic teaching materials to improve reading skills of Islamic Economics study program students at the University of Darussalam Gontor?" and "How effective are Arabic teaching materials in improving reading skills of Management study students at the University of Darussalam Gontor?". This study aims to explain the characteristics of the Arabic language teaching materials in improving the reading skills of students in Islamic Economics study programs at the University Darussalam of Gontor and to see the effectiveness of Arabic teaching materials to improve reading skills of students in Islamic Economics at the University of Darussalam Gontor.

This research is a type of Research and Development (R \& D) research which is preceded by data collection with interviews, tests, questionnaires, and documentation. To analyze the data collected, the author uses the t-test formula.

The results of this study that teaching materials are arranged in the form of books, which are preceded by supervising for instructors of Arabic, learning steps, and syllabus. And the core of this book is material consisting of 13 chapters, consisting of reading texts and practice questions. At the end of this book, there are vocabulary words and their meanings arranged according to the alphabet. From the results of the pre-test and post-test values, it was found that the post-test value was greater than the pre-test. This shows that the compiled book is used both for students and instructors of Arabic. Then the Arabic language instructors must pay attention to the things students need to learn Arabic by looking at the condition of the students and their language skills.

From the results of this discussion, researchers hope that lecturers of Arabic language material will always pay attention to the needs of students, so they can choose the right material and learning methods and according to their needs.
\end{abstract}

Keywords : Arabic Language Material, Reading Skill, Teaching Material Drafting, Islamic Economics Study Program. 
الكريم. وهي أقدر اللغات التي تعين المفكر

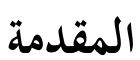

$$
\text { والمتدبر على فهم آيات الله. }
$$

ابتدأ تعليم اللغة بأربع مهارات هي:

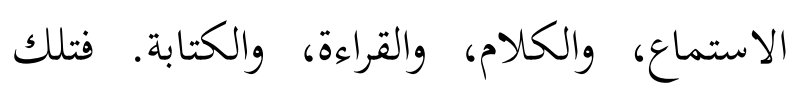


تسمح للفرد بفهم وإنتاج لغة منطوقة من أجل

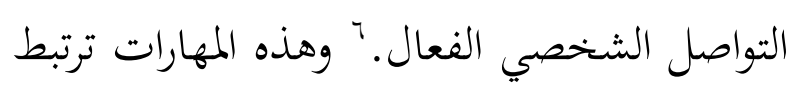
بعضها ببعض. وتنقسم المهارات إلى قسمين،


والمهارات الإنتاجية هي القراءة والكتابة. v أنّ القراءة عملية تحسين الأفكار وإخصاب حياة القارئ، النافذة التي نطل منها ألوان الثقافة وضروب المعارف الإنسانية. فأصبح

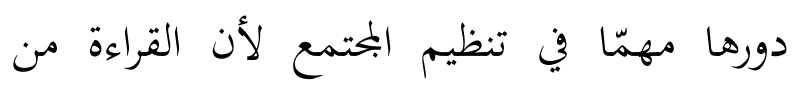

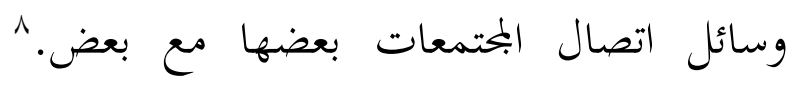
فجودة الطلاب في القراءة تساعدهم على فهم

•علي أحمد مدكور، تدريس فنون اللغة العربية،

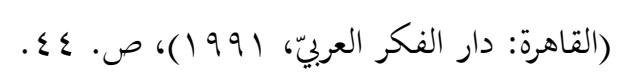


حديثة في تدريس اللغة العربية، (الأردن: عالمَ الحرون، الجامتب

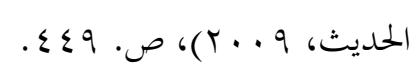

لعمر صديق عبد الله، تعليم اللغة العربية للناطقين

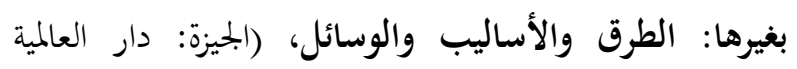

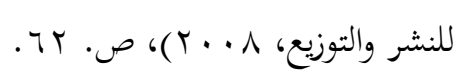

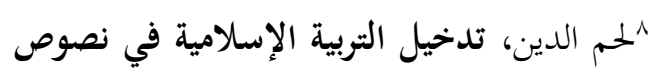

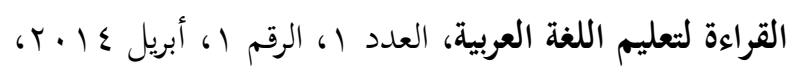

تعتبر اللغة العربية ذات أهمّية كبيرة في حياة الفرد والمختمع،' وهي أداة الاتصال بين بحموعة من الجنس البشري ووسيلة التفاهم




شديدة إلى المترسّخين في هذه اللغة، لأغّا تعتبر إحدى اللغات التي امتازت من بين سائر لغات

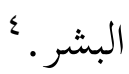
إنّ عالمية الدعوة الإسلامية والإنسانية تجعل من الضروري الاهتمام بتعليم وتعلّم اللغة العربية للناطقين بها وللناطقين بغيرها من العرب الصنموري

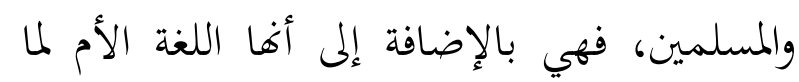


فإها لغة مقدسة لما يربو على ألف مليون مسلم

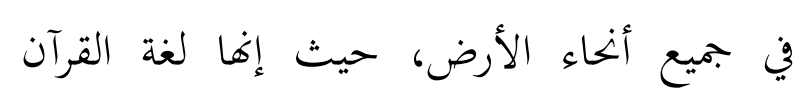

'علي إسماعيل محمد، المنهج في اللغة العربية،

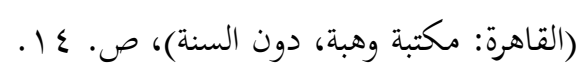

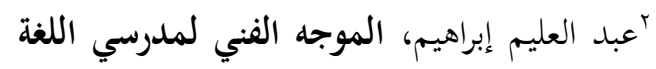

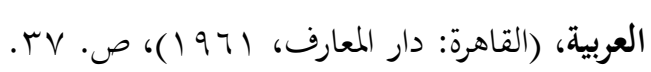


ماهيتها وطرائق تدريسها، الطبعة الأولى، (الرياض: دار المسلم

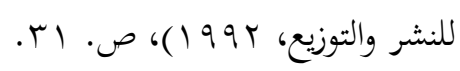

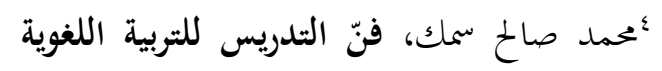
وانطباعاتها المسلكية وأنماطها العملية، (القاهرة: دار الفكر لـرك

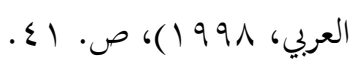


دور كبير في مساعدة الطلاب لهذا المستوى على

اكتساب المعلومات وتخزينها واستعماهلا. "

إن المواد التعليمية على درجة كبيرة من

الأهمية، وتأتي على المرتبة الأولى قبل الأدوات

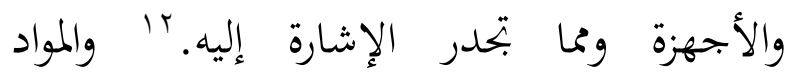
التعليمية هي المواد المصنفة والمنظمة والمرتبة في

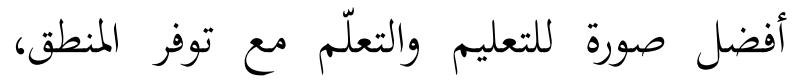
والاقتصاد في الفكر والفائدة والواقعية والقابلية للفهم. وهي أفضل عدة وأمضى سلاح للتعامل مع مشكلات الحياة. يفيد الطالب من دراسته لها في تنمية قدراته لاستيعاب المزيد من الحقائق



إن للمواد التعليمية وظائف عدة، منها أن

يقدم المعرفة العلمية للطالبات في صورة منظمة فيساعدهم على استيعاها، وإدراك الترابط بين

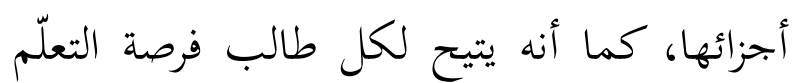



"'فتحي علي يونس وآخرون، أساسيات تعليم اللغة

العبية والثربية الدينية، (القاهرة: دار الثقافة للطباعة والنشر،

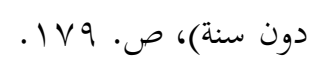

"'عبد العظيم عبد السلام الفرجاني، تكنولوجيا

إنتاج المواد التعليمية، (القاهرة: دار غريب للطباعة والنشر، البرا،

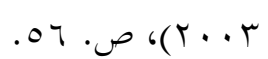

"'إبراهيم بسيوني عميرة، المنهج وعناصره،

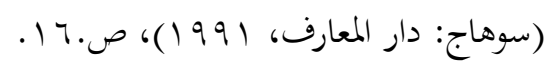



تدريسها، (بيروت: دار النفائس: 999 (1)، ص. ع זبك.
جميع ما قرأها من الكتب أو المقالات، حتى تساعدهم للحصول على قدرة قراءة الكتب حتى مراه يتعلّموا ويفهموا أفكارهم.

ومن الجامعات الإسلامية التي تعتبر خبيرا

في بحال نشر اللغة في إندونيسيا هي جامعة دار السلام كونتور. إن الجحامعة حريصة على تطوير العلوم الإسلامية والكونية. وجعل اللغة العربية والإبحليزية لغتي التدريس والتخاطب بين الطالبات

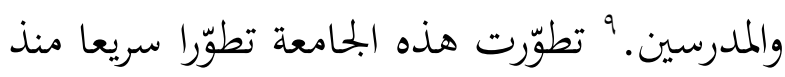
عام ع ا. ץ. وقسم الاقتصاد الإسلامي قسم جديد في الجحامعة الذي يزود طلابه بالعلوم والمعلومات، منها تزويد اللغة العربية. إن تعليم اللغة العبية مهمّ للطلاب لاستعدادهم في كتابة رسالة البحث وقراءة الكتب العربية وفي الأعمال

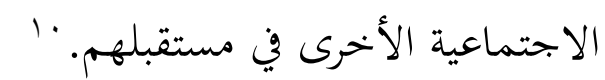
إنّ تعليم اللغة العربية لقسم الاقتصاد الإسلامي يحتاج إلى الأسس القوية في أول نشأته.

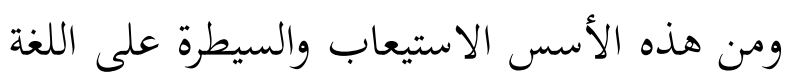
العربية خاصة في هذا المحال. وذلك في جميع فنونه ومهاراته خاصة في مهارة القراءة، باعتبار أنّ له في فئل "معهد دار السّلام كونتور للتربية الإسلامية الحديثة، وردون رسالة آخر السنة بثلاث لغات العربية والإنجليزية والإندونيسية، (كونتور فونوروكو، ع (ب. ب)، ص. 9. ·'نتيجة الحوار مع رئيس قسم الاقتصاد الإسلامي

بجامعة دار السلام كونتور، ه فبراير 1 | • ؟. 
بأنفسهم. V' وتأتي مواد التعليم لتكمل عناصر

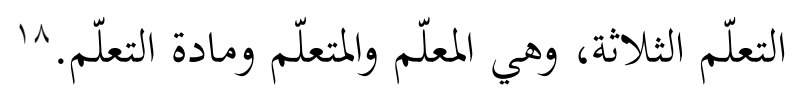

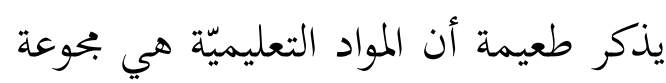

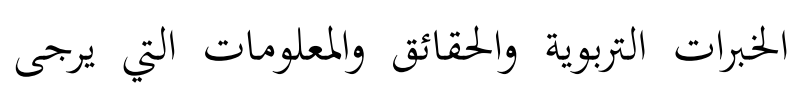
تزويد الطالبات بها والاتحاهات والقيم التي يراد تنميتها عندهم أو المهارات الحركية التي يراد

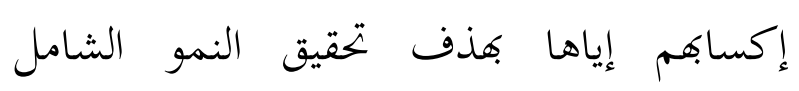

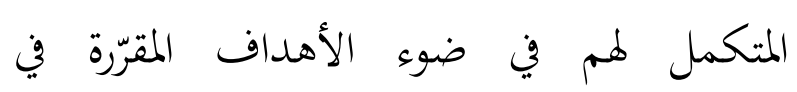
المنهج 19 خطوات تصميم المواد التعليميّة تشير أدبيات تصميم إنّ هناك خطوات

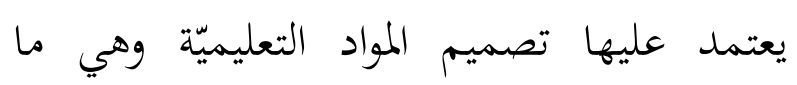
يلي: بع بع 1 المرحلة التحضيرية

هذه المرحلة هي مرحلة أساسية، فهي تمدّ المعلّم بأداة الإعداد من الجوانب النظرية

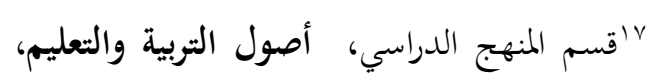

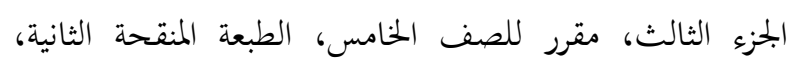

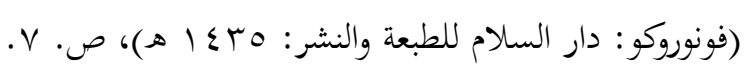

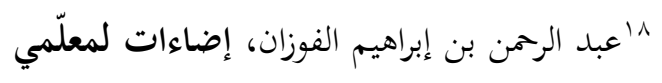
اللغة العربية لغير الناطقين بها، الطبعة الأولى، (الرياض: د.

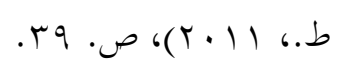
9'رشدي أحمد طعيمة، المرجع في تعليم اللغة صابة العربية للناطقين بلغات أخرى، الجزء الأول، القسم الثاني،

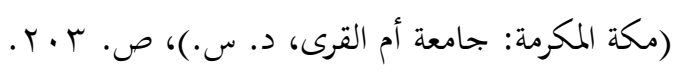


اللغة العربية ........ ص. ص. V. V.
وفي الدراسة التمهيدية وجدت الباحثة أن المواد التعليمية في درس اللغة العربية لقسم الاقتصاد الإسلامي بجامعة دار السلام كونتور لم

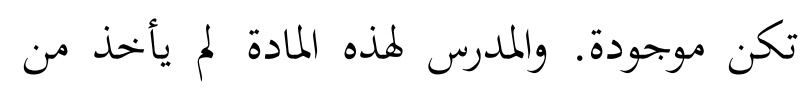

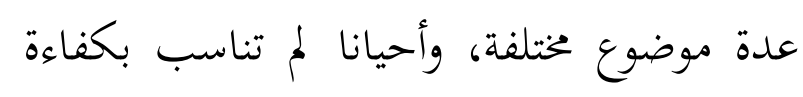
الطالبات. 10 فالطالبات يصعبن في تعلّم درس ورس اللغة العربية لأن المادة غير جذابة. وهذا يظهر أن

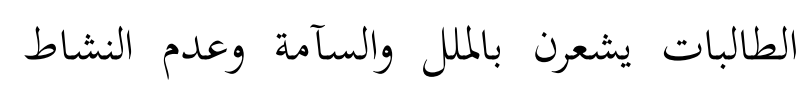
عند أداء التعليم في المحاضرة. 17 بهذه الأحوال حاولت الباحثة إلى تصميم

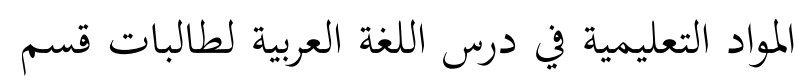
الاقتصاد الإسلامي بجامعة دار السلام كونتور مؤسسا على الدراسة التمهيدية التي أجرتا الباحثة. تسهيلا للمحاضرين القيام بالعملية

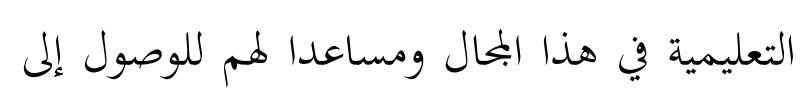
الأهداف المنشودة.

\section{مفهوم المواد التعليميّة} إنّ كلمة المواد هي جمع من المادّة، فالمادّة

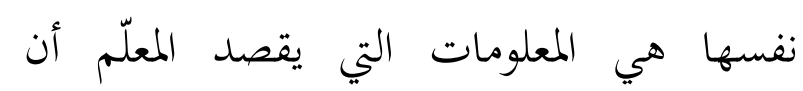

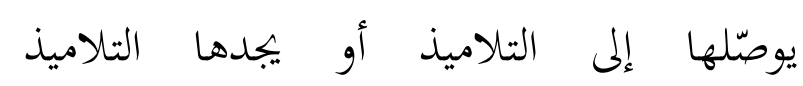

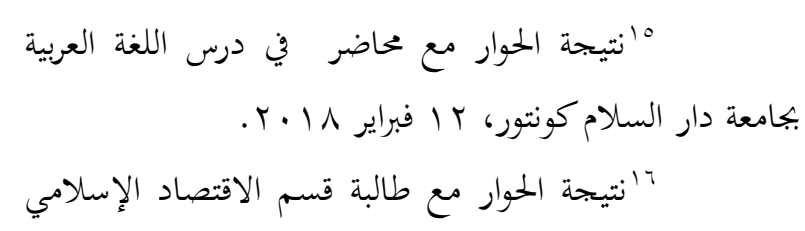

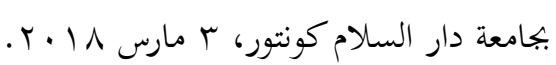


أ) دراسة كتب تعليم اللّغة العربية لغير الناطقين ها وكتب منهج البحث في طريقة تحليل البيانات.

ب) دراسة المشكلات والصعوبات المتصلة بتعلّم المهارات اللّغوية.

ج) دراسة المنهج الدراسيّ والأهداف في التعليم.

Y. مرحلة جمع النصوص الخاصّة والمراجع.

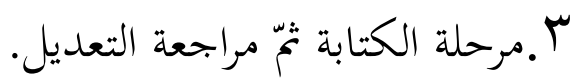
؟.رحلة إجراء الكتاب حيث كتب في منهج

$$
\text { البحث. }
$$

๑مرحلة طباعة الكتاب.

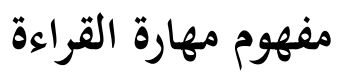

يذكر محمود كامل الناقة القراءة أداة تتّسم

بدوام الاستمرار والاستخدام من حيث هي أداة


الاتِصال بالإنتاج الفكريّ والأدبيّ والحضاريّ


الحاضر. r ويعرف كوتريل Cottrell المهارة هي القدرة

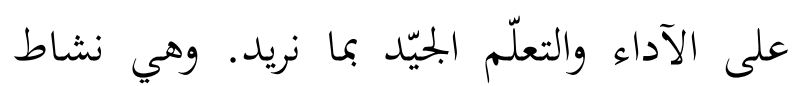

- تحليله - تقويمه، (مكة المكرّمة: جامعة أم القرى،

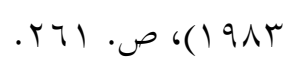

كابعمود كامل الناقة، تعليم اللغة العربية للناطقين



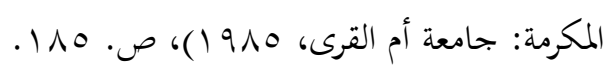

والأمور التطبيقية من كتب أعدّت لتعليم اللّلغة العربيّة لغير الناطقين بها. تنقسم هذه المرحلة

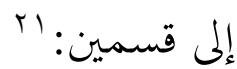
أ) تطوير ذات المؤلّف في ميدان التأليف

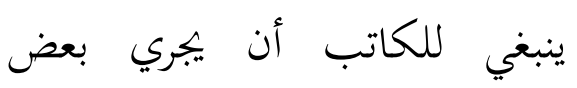

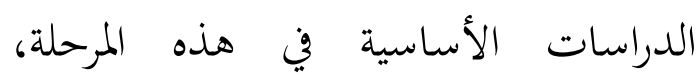
ويقصد بالدراسات الأساسية هنا ما يجريه المؤلّف أو يستعين به من دراسات سابقة

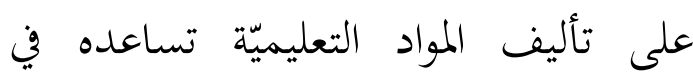
إعدادها على أساس علميّ وليس بحرّد آراء خاصة وتصوّرات ذاتية.r ب) دراسة خصائص الدارسين وبيئتهم تعدّ هذه الخطة على الجوانب النفسية للدارسين، ينطوي على دوافعهم


اللّلغة العربيّة. كذلك النظر إلى البيئة التي يعيشون فيها. تعدّ هذه المرحلة التحضيرية إلى الأعمال

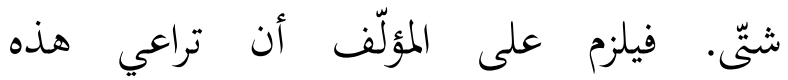
الأعمال:rr

ابعبد الرمن بن إبراهيم الفوزان، إضاءات لمعلّمي

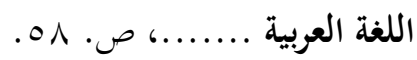
بr ألمرجع نفسه، ص. rrrr الأساسي لتعليم اللغة العربية للناطقين بلغات أخرى: إعداده 
Y.الاهتمام بميول الطلاب القرائية والإفادة منها

$$
\text { في تشجيعهم على المطالعة. }
$$

ץ.الاهتمام بطبيعة إدراك الأطفال للأشياء.

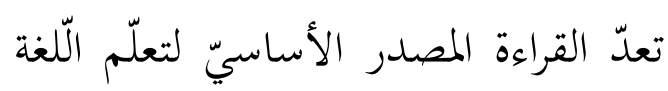

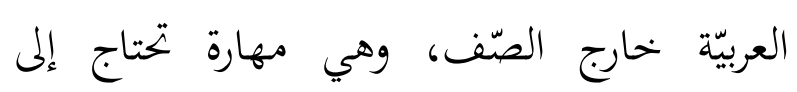



$$
\begin{aligned}
& \text { أربع مهارات:^^ } \\
& \text { ا ـمهارات التعرف مهارات }
\end{aligned}
$$

يقصد بالتعرف هنا القدرة على فكّ

الرموز المكتوبة والربط بين صوت الكلمة

وصورقا وتمييزها عن غيرها من الكلمات. إنّا

عملية ميكانيكية ينتهي الأمر فيها عند نطق ومن وميزها

الكلمة نطقا صحيحا.

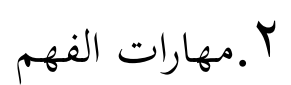

ويدرك بالفهم هنا القدرة على إدراك

العلاقة بين معاني الكلمات والجمل وفهم

الدلالات التي تعبّر عنها سواء أكانت

$$
\text { دلالات مباشرة أو غير مباشرة. ‘r }
$$

العبلة لعبد الرمن بن إبراهيم الفوزان، إعداد مواد تعليم

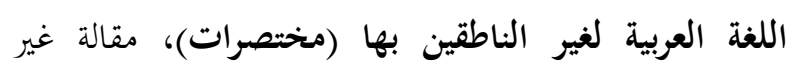

$$
\text { منشورة، (N) }
$$

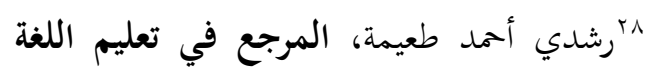

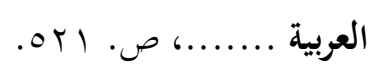

9'عبد الرمن بن إبراهيم الفوزان، إعداد مواد



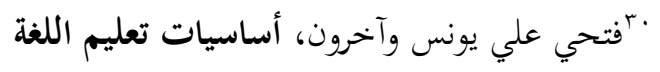

. إ.......
متعلّم يتمّ تطويره خلال ممارسة نشاط ما تدعمه التغذية الراجعة.

فمهارة القراءة هي نشاط عقلية تشمل تفسير الرموز التي يتلقها القارئ عن طريق عينيه

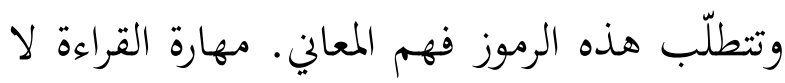
يكفي بذكاء الطالب، بل يهتمّ بوجود العوامل

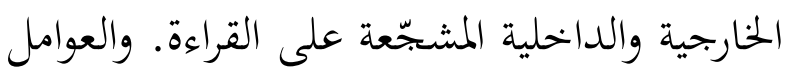
الخارجية المشجّعة على القراءة هي: ا أتأمين الجوّ المناسب للقراءة.

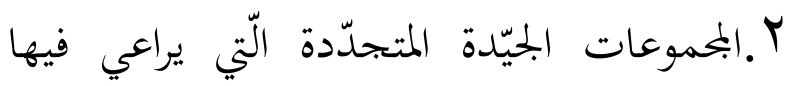

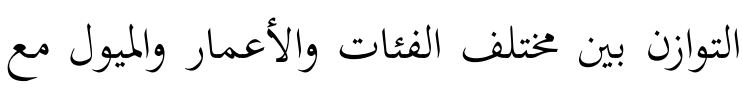
تنوّع الأوعية التقليدية منها والرقمية. والمثال: أ) إنشاء نوادي القراء والجمعيات الثقافية. ب) عقد الندوات والأمسيات الثقافية والمناظرة

$$
\text { الأدبية والعلمية. }
$$

ج) توجيه العناية خاصّة لنشر الكتاب

$$
\text { للطالب. }
$$

$$
\text { د) حسن التأهيل وتدريب من المدرسة. }
$$

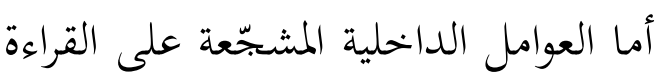

ا ـاحترام الطلاب وإدراك الفروق الفردية بينهم.

• هبة محمد عبد الحميد، أنشطة ومهارة القراءة



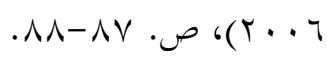

"هषبة محمد عبد الحميد، أنشطة ومهارة القراءة




تتطلّب أعماها قدرا معيّنا من اللّغة الأجنبية التي

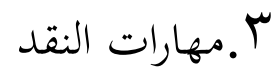

يمكن توظيفها في هذه الأعمال.

وتعتبر تعليم اللّغة العربيّة لأغراض خحاصّة

مدخل خحاص من مداخل تعليم الّلغة الّذي يركّز

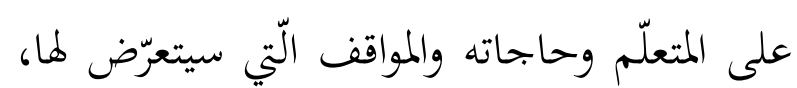
وكان المنهج المستخدم له كغيرها من المناهج تركّز على المتعلّم وحاجاته والأغراض التي يتعلّم اللّلغة تمني

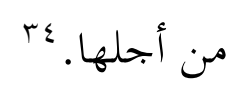

ويعدّ تعليم اللّغة العربية لأغراض خحاصّة هو نوع من التعليم الذي جددت مواد مقرراته، بصفة رئيسية، وفق تحليل مسبق للحاجات الإبلاغية للمتعلّم، وليس على أساس تفضيل

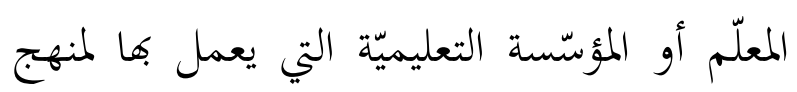

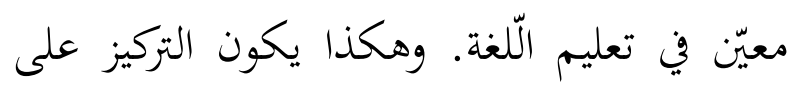

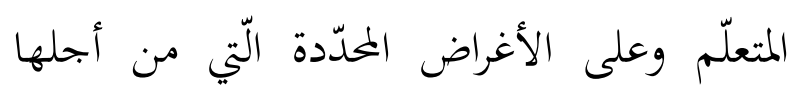

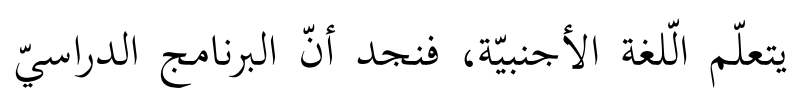

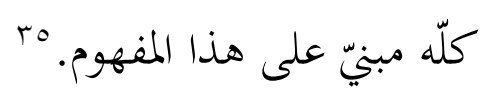



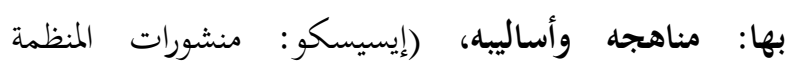

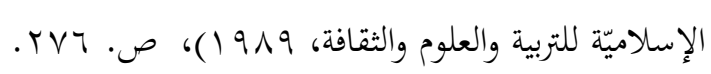

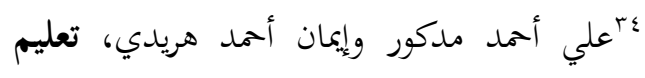
اللغة العربية لغير الناطقين بها: النظرية والثطبيق، (القاهرة:

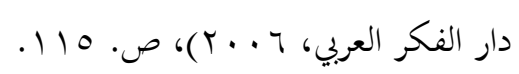

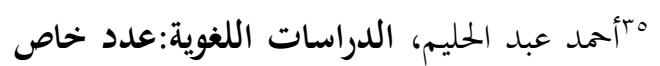
تعليم اللغة العربية لغير الناطقين بها، (سودان: بشركة فال

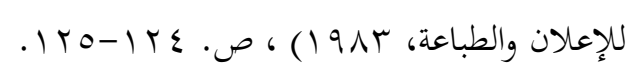

ويفهم بالنقد هو القدرة على الحكم



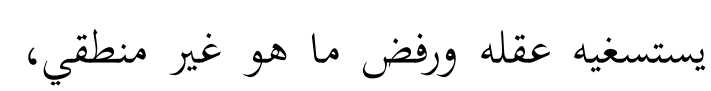



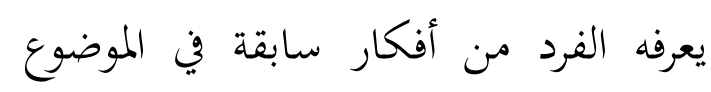
نفسه. 'ب العرد

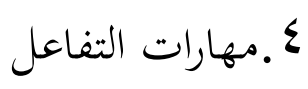

أما التفاعل هنا النشاط الفكري المتكامل الذي يقوم به الفرد عند اتصاله بمادة مطبوعة والذي يبدأ بإحساس مشكلة تواجهه، والبحث من خلال المادة المقروءة عن حلّ هذه المشكلات والاستجابة لهذا

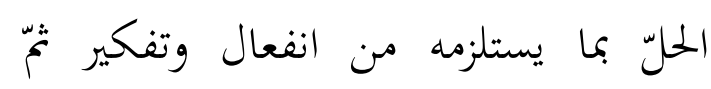

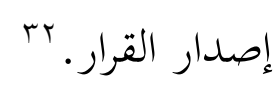

مفهوم تعليم اللّغة العربية لأغراض خحاصة إصلة هناك مستويان في تعليم اللّلغة العربيّة كلغة ثانية، هما: المستوى اللّغوي العام والمستوى اللغوي التخصصي. ويقصد بتعليم اللّة العربيّة لأغراض خاصة Language for spesific purpose هي تعليم اللّغة لأغراض وظيفية محدّدة ولفئات خحاصّة وطرأمد فؤاد محمود علهان، المهارات اللغوية:



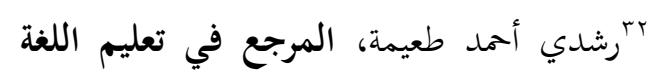

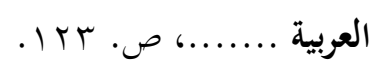


العربيّة والمواقف التي ينوي استخدام اللّغة

$$
\text { فيها. }
$$

"ا.التركيز على اللّغويات و والمهارات وأساليب

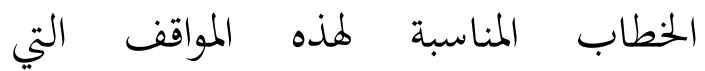

$$
\text { سيستخدم فيها متعلّم اللّغة. }
$$

يستخدم هذا البحث المدخل الكمي

والكيفي. وهذا البحث على أسلوب منهج

البحث والتطوير Research \& Development، وهي الطريقة المستخدمة للحصول على نتائج


التي تحتاج إلى حلّ مع منتج معيّن. بَr وتقوم الباحثة بالبحث في تصميم المنتج الجلديد واختباره.

يتكوّن بحتمع البحث من طالبات قسم

الاقتصاد الإسلامي للفصل الرابع بجامعة دار الستّلام كونتور مانتينجان بناوي جاوى الشرقية هو بـ طالبة، وقسمت الباحثة في اختيار العينة للتجربة الأولى في • ا طالبة وللتجربة الثانية في r r r r بلبة.

الخطوات التي أجرت الباحثة في تصميم

المواد التعليمية لدرس اللغة العربية لطالبات قسم

${ }^{39}$ Sugiyono, Metode Penelitian Kuantitatif, Kualitatif dan $R$ \& $D$, Cetakan XX, (Bandung: Alfabeta, 2014), p. 297.

\section{أهمّية تعليم اللّغة العربية لأغراض خاصة} تعتبر تعليم اللّغة العربية لأغراض خحاصة


فحسب، ولكنّها بالإضافة إلى ذلك وسيلة

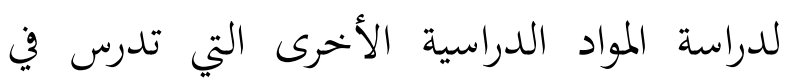
مختلف المراحل التعليميّة. وإذا استطعنا أن نتصور لتروية شيئا من ظواهر العزلة والانفصال بين المواد الدراسية، فلا يمكننا أن نتصوّر هذا الانفصال بين

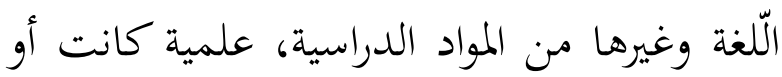
أدبية. وإذا كانت اللّلغة العربية هي مادة التخصّص لمدرّس اللّلغة العربيّة، فهي بالنسبة إلى فريه سائر المدرّسين مفتاح المواد التي يقومون بتدريسها، كما أثّا وسيلتهم الأولى لقراءة مراجع التي

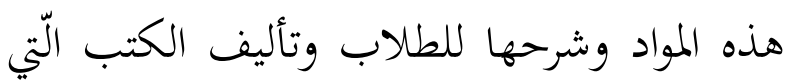

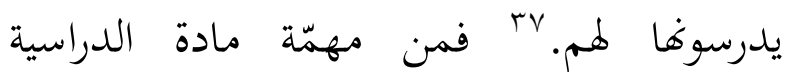

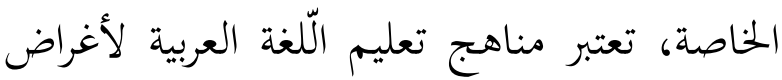

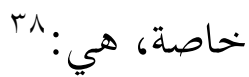
ا (التركيز على المتعلم وحاجاته الخاصة.

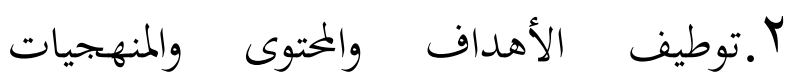
التدريسية لإعانة الدارس على استخدام

بَ"علي أممد مدكور، تدريس فنون اللغة العربية .

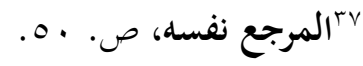


اللغة العربية ....... ص. • ـ1-11. 
الناطقين بها خاصّة لتنمية مهارة

القراءة، ولفهم الأشكال والمعايير

للمواد التعليميّة الجيّدة.

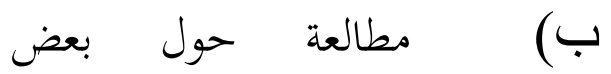

الكتب في منهج البحث العلمي

لفهم الخطوات الجحارية في تصميم

$$
\text { المواد التعليميّة. }
$$

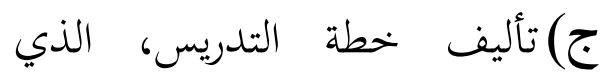

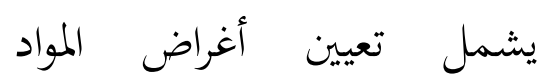

$$
\text { والكفاءة الأساسية. }
$$

د) اختيار الموضوع والمواد المناسبة وأنواع التدريبات في القراءة.

$$
\text { 0) تنظيم المواد التعليميّة. }
$$

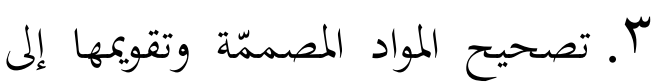

الخبير تخم تحسينها، فيقصد منها

الحصول على المدخلات والاقتراحات

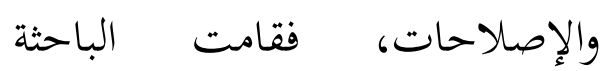

بتصحيح منتجها لتخفيف العيوب.

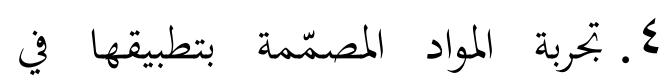

العملية التعليميّة، ففي هذه الخطوة

عقدت الباحثة الاختبار على منتجها

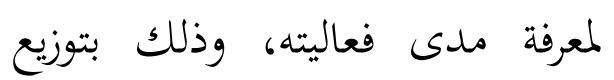

$$
\text { الاستبيان إلى الطالبات والمحاضر. }
$$

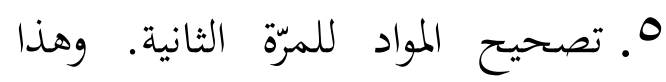

التصحيح مؤسّسا على نتائج التجربة

الأولى حتى تأتي المواد أجود ميّا بعد.
"Borg” الاقتصاد الإسلامي تعتمد على طريقة

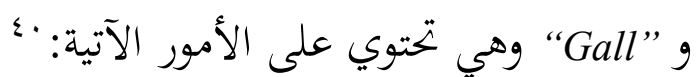

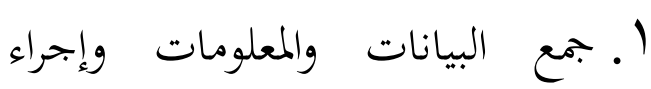

الدراسة التمهيدية، لمعرفة المشكلات

حول تعليم وتعلمّ اللّغة العربيّة في

قسم الاقتصاد الإسلامي. وفي هذه

الخطوة قامت الباحثة بهذه الأعمال:

أ) الحوار مع رئيس قسم الاقتصاد

الإسلامي لمعرفة الرسالة والهدف

$$
\text { في قسم الاقتصاد الإسلامي. }
$$

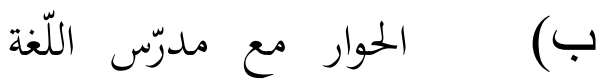

العربيّة لمعرفة أحوال التعلّم والتعليم

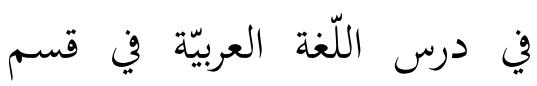

$$
\text { الاقتصاد الإسلامي. }
$$

ج) الحوار مع بعض طالبات قسم الإنمي

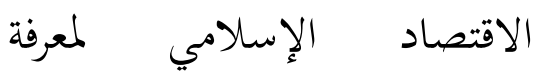

المشكلات في تعلّم اللّغة العربيّة

$$
\text { في قسم الاقتصاد الإسلامي. }
$$

ץ. تخطيط وتصميم المنتج على أساس

نتائج الدراسة التمهيدية، لمعرفة كفاءة

$$
\text { الطالبات. وفيها الخطوات الآتية: }
$$

أ) مطالعة حول بعض الكتب في

تعليم اللّغة العربيّة لفهم الخطوات

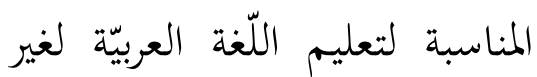

40 Adelina Hasyim, Metode Penelitian dan Pengembangan di Sekolah, (Yogyakarta: Media Akademi, 2016), p. 86. 
تقوم الباجثة بتحسين المواد التعليمية على أساس هذه النتائج حتى تأتي المواد التعليميّة بشكل أفضل.

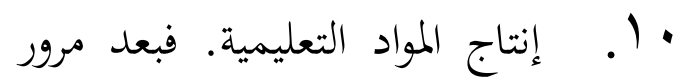
الباحثة نخو هذه الخطوات جميعا، تتمّ عملية تصميم المواد التعليمية. الرسم البياني رقم (1)

\section{مراحل تنفيذ الدراسة}
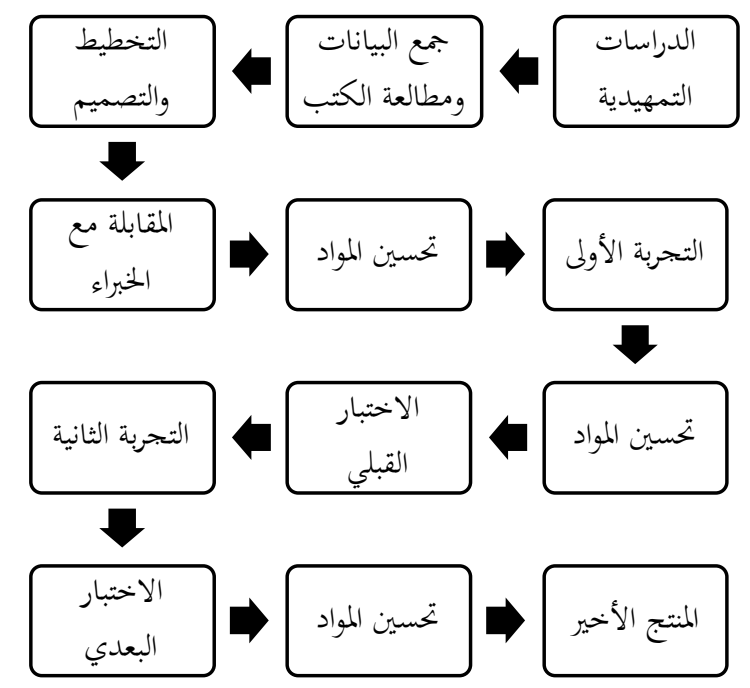

في تحليل نتائج الاختبارين القبلي والبعدي، استخدمت الباحثة برنامج كPSS الإصدار 7 أ6. وهي ما يلي:
الجدول رقم (1)

الحساب بأسلوب t-Test بطريقة SPSS

\section{Paired Samples Statistics}

\begin{tabular}{|l|l|c|c|c|c|}
\hline \multicolumn{2}{|l|}{} & Mean & N & $\begin{array}{c}\text { Std. } \\
\text { Devia } \\
\text { tion }\end{array}$ & $\begin{array}{c}\text { Std. } \\
\text { Error } \\
\text { Mean }\end{array}$ \\
\hline \multirow{2}{*}{$\begin{array}{l}\text { Pair } \\
1\end{array}$} & $\begin{array}{l}\text { Pre_Test } \\
\text { Prest- }\end{array}$ & 5,34 & 32 & 1,789 &, 316 \\
\hline $\begin{array}{l}\text { Pest } \\
\text { Test }\end{array}$ & 7,06 & 32 & 1,480 &, 262 \\
\hline
\end{tabular}

7. الاختبار القبلي، ففي هذه الخطوة

اختارت الباحثة منتجها في المكان الأوسع مّّا سبق بجميع عينة البحث. والهدف من هذا الاختبار هو معرفة كفاءة الطالبات قبل استخدام المواد التعليميّة المصمّمة. V. التجربة الثانية للمواد التعليميّة المصمّمة. بعد إجراء التجربة الأولى وتحسين المواد على أساس مدخّلات المحاضر و والطالبات، تقوم الباحثة بتجربتها مرّة أخرى مع عدد الطالبات

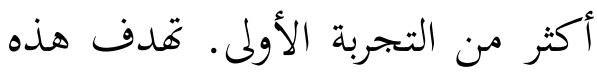

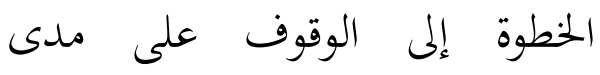
صلاحية المواد التعليميّة بعد تحسينها للمرّة الثانية. وفي فاية التجربة، تقوم الباحثة بتوزيع أوراق الاستبيان للمحاضر والطالبات للوقوف على لب ليع مدى صلاحية المواد التعليميّة

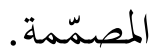
^. الاختبار البعدي. تقوم الباحثة في فاية العملية التعليمية بعقد الاختبار البعدي، وذلك للوقوف على مدى فعالية المواد التعليمية بعد تحسينها


9 . تحسين المواد التعليمية. بالنظر إلى نتائج الطالبات ونتائج الاستبيان، 


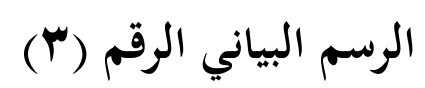

مقارنة نتائج الاختبار القبلي والاختبار البعدي

مقارنة نتائج الاختبار القبلي والاختبار

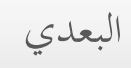

$\mathbf{5 , 3 4 3 7 5}$

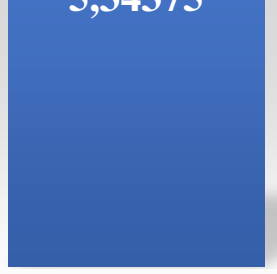

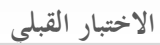

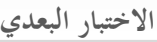

فمن هذه المقارنة قد تبيّن أنّ نتيجة الانّا

اختبار فرضية البحث مردودة. معنى ذلك، أنّ لهن هناك اختلافا ملحوظا بين معدل نتائج الطالبات في الاختبار القبلي ومعدل نتائج الطالبات في

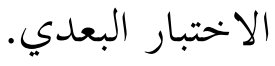

على المدرّس أو المحاضر أن يهتمّ بأمور معيّنة قبل بداية تعليم اللّلغة العربيّة، وهي المواد المدروسة والتدريبات وطريقة التعليم وغير ذلك. فطالبات قسم الاقتصاد الإسلامي بجامعة دار السّلام كونتور في شدّة الاحتياج إلى المواد التعليميّة في درس الّلغة العربيّة لتنمية مهارة القراءة وهي بلمال الاقتصاد الإسلامي. وذلك ليكون تعليم اللّغة العربيّة في قسم الاقتصاد الإسلامي يصل إلى أقصى أغراضها.

تركّز هذه المواد التعليميّة لتنمية مهارة

القراءة لمحال الاقتصاد الإسلامي. لهذا اختارت الباحثة الموضوعات التي تبحث في الاقتصاد
Paired Samples Correlations

\begin{tabular}{|l|l|r|r|c|}
\hline \multicolumn{2}{|l|}{} & N & Correlation & Sig. \\
\hline Pair 1 & $\begin{array}{l}\text { Pre_Test } \\
\text { \& Post- } \\
\text { Test }\end{array}$ & 32 &, 893 &, 000 \\
\hline
\end{tabular}

\begin{tabular}{|c|c|c|c|c|c|c|c|c|c|}
\hline & \multicolumn{5}{|c|}{ Paired Differences } & \multirow[t]{3}{*}{$\mathrm{t}$} & \multirow[t]{3}{*}{$\mathrm{df}$} & \multirow{3}{*}{\begin{tabular}{|l} 
Sig \\
$\dot{(2-}$ \\
tail \\
ed $)$ \\
\end{tabular}} \\
\hline & & \multirow[t]{2}{*}{\begin{tabular}{|c|} 
Mea \\
$n$
\end{tabular}} & \multirow[t]{2}{*}{$\begin{array}{c}\text { Std } \\
\cdot \\
\text { De } \\
\text { via } \\
\text { tio } \\
\mathrm{n}\end{array}$} & \multirow[t]{2}{*}{\begin{tabular}{|c|} 
Std. \\
Erro \\
r \\
Mea \\
n
\end{tabular}} & \multicolumn{2}{|c|}{$\begin{array}{c}95 \% \\
\text { Confidenc } \\
\text { e Interval } \\
\text { of the } \\
\text { Difference }\end{array}$} & & & \\
\hline & & & & & $\begin{array}{c}\text { Low } \\
\text { er }\end{array}$ & $\begin{array}{c}\text { Upp } \\
\text { er }\end{array}$ & & & \\
\hline $\begin{array}{l}\text { Pai } \\
\text { r } 1\end{array}$ & \begin{tabular}{|l} 
Pre_T \\
est - \\
Post- \\
Test \\
\end{tabular} & $\begin{array}{r}- \\
1,71 \\
9\end{array}$ & $\begin{array}{r}, 81 \\
3\end{array}$ &, 144 & $\begin{array}{r}- \\
2,01 \\
2\end{array}$ & $\begin{array}{r}1,42 \\
6\end{array}$ & $\begin{array}{r}- \\
11, \\
965\end{array}$ & 31 & $\begin{array}{r}, 00 \\
0\end{array}$ \\
\hline
\end{tabular}

Paired Samples Test

يظهر من الجحدول السابق أنّ قيمة ت-


لذلك فإنّ الفرضية الصفرية مردودة. أي معنى ذلك، أنّ هناك اختلافا ملحوظا بين معدل نتيجة العرصيه الحمريه مردوده الطالبات في الاختبار القبلي والاختبار البعدي. ومقارنة نتائج الاختبار القبلي والاختبار

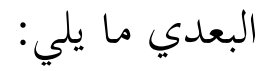


درس اللّغة العربيّة. وتظهر من الرسم البياني السابق أنّ نتائج الاختبار البعدي أكبر من نتائج

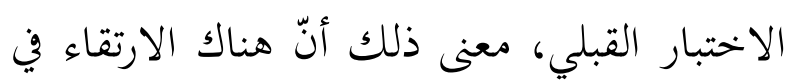

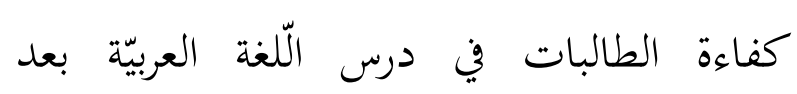
استخدام المواد التعليميّة المصمّمة.

وكانت سهولة عملية التعليم والتعلّم لدى

طالبات قسم الاقتصاد الإسلامي لكون المواد

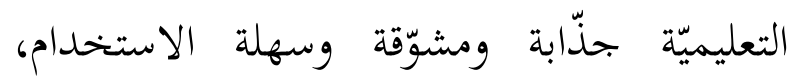
بالإضافة إلى أنّ الموضوعات فيها مناسبة بيئتهنّ،

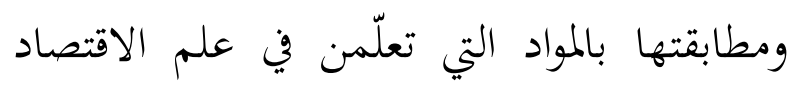


مناسبة بمستوى كفاءة الطالبات. وتعتبر هذه المواد التعليميّة جذّابة في كوها ملوّنة وفيها صور متنوّعة مناءه

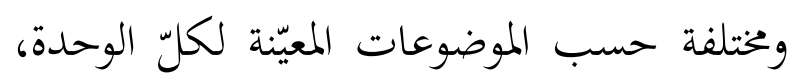

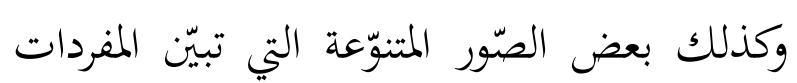
المستخدمة فيها.

وخحلاصة القول أنّ تصميم المواد التعليميّة

قد تؤثر في ترقية مهارة القراءة لدى طالبات قسم الاقتصاد الإسلامي، بالإضافة إلى الختيار الموضوعات المناسبة واستخدام الألوان المختلفة الإنسافي التي تحمل إلى نشاط الطالبات في تعلّم درس اللّلغة العربيّة. والألوان المستخدمة هي الأحمر والأسود

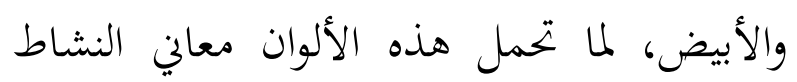
والحبّ والفرح و والسّلام والقوة والإحساس بالكثافة.
الإسلامي. وهي الموضوعات التي لا يخلو من الأساسيات الأربعة. وكتبت الباحثة النصوص

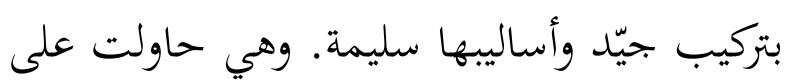

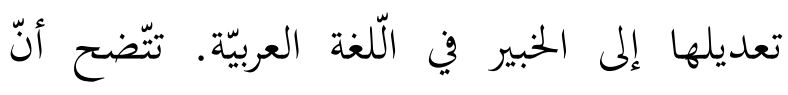

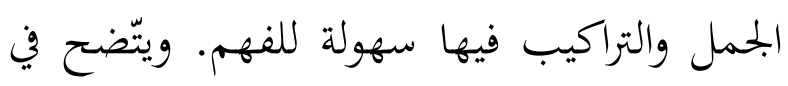
محاولة الطالبات على فهم تلك النصوص وفهم التراكيب النحوية. واختارت الباحثة المفردات التخصّصية حول الاقتصاد الإسلامي، لتكون المواد مطابقا لتعليم اللّغة العربيّة في مجال الاقتصاد الإدياد الإسالامي. أعدّت الباحثة طريقة التدريس لتشجيع الطالبات في تنمية مهارة القراءة، واختارت طريقة

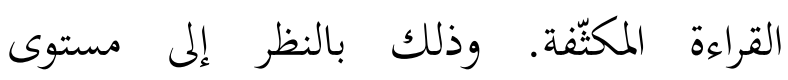
الطالبات هي مستوى الجامعة وتسمّى بمرحلة

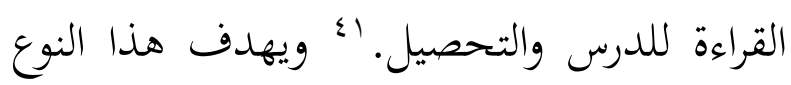
من القراءة إلى تكثيف نشاط القراءة في الفصل من أجل تعميق دراسة اللّغة وزيادة الكفاءة فيها،

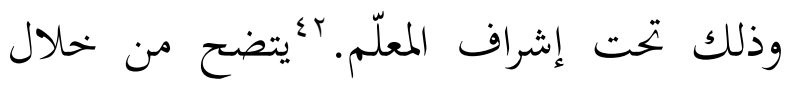
هذه النتائج، أن الطالبات يستطعن على فهم المواد التعليميّة بسهولة وارتقت كفاءهنّ في فهم ا"حمود كامل الناقة ورشدي أمد طعيمة، طرائق تدريس اللغة العربية لغير الناطقين بها، (إيسيسكو: منشورات

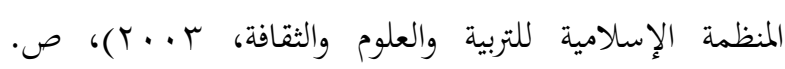
.104 r بممود كامل الناقة، تعليم العربية لغير الناطقين 
وتطوّره، وجوانب الدراسة الاقتصادية،

والمشكلة الاقتصادية، وبعض المفاهيم

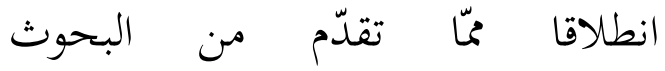

الاقتصادية، وقانون الأثمان (الطلب)، وقانون والتحليلات، يمكن اعتبار هذه المواد التعليميّة الأثمان (العرض)، وتحديد سعر التوازن وكمية التوازن في السوق، والأسواق، والنقود، والنقود

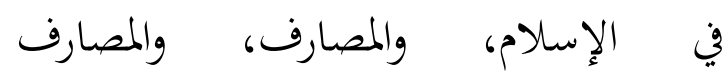
الإسالامية.

وتحتوي لكلّ وحدة على الغلاف

الداخلي، والكلمات الجديدة، و والمقالة الرئيسيّة للدرس، والتدريبات. تهدف التدريبات لمعرفة مدى فهم الطالبات نهو الموضوع. وهي تنقسم على خمسة التدريبات، وهي: إجابة الأسئلة المتعلّقة بالنصّ، واختيار

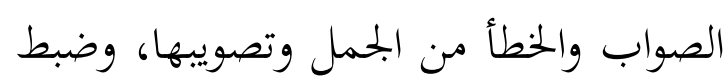

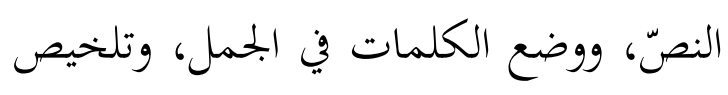
النصّ.

استخدمت الباحثة صورا تناسب موضوعات المواد التعليميّة في نصّ القراءة. وبجانب ذلك، استخدمت الباحثة كذلك الصور المتنوّعة لبيان معاني المفردات الجحديدة. وهي لتسهيل الطالبات في فهم موضوعات الدرس وفهم أنواع المفردات المستخدمة فيها.

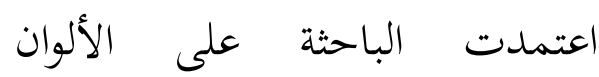

المتنوّعة، تمدف في جذب رغبة الطالبات في تعلّم درس اللغة العربية وغرس حِّهنّ في القراءة. وفي اختيار هذه الألوان اعتمدت مناسبة لتعليم درس اللغة العربية لتنمية مهارة القراءة لمحال الاقتصاد الإسلامي في جامعة دار السّلام كونتور جيّدة، لما لها التأثير في تنمية مهارة القراءة للطالبات فيها. وقد مرّت بالتصحيحات والتعديلات بعد تقديمها إلى الخبراء وإجراء التجربة. ومن الممكن القول إنّ هذه المواد التعليميّة فعّالة لتعليم اللغة العربية بمحال الاقتصاد الإسلامي في جامعة دار السلام كونتور. ومن نتائج هذا البحث ما يلي: الإسطي ا ـمواصفات المواد التعليمية لدرس اللغة مداتيح العربية لتنمية مهارة القراءة لطالبات قسم الاقتصاد الإسلامي بجامعة دار السلام كونتور

المواد التعليمية المصمّمة لمحال الاقتصاد الإسلامي هي تأتي على شكل الكتاب المطبوع. تهدف لتنمية مهارة القراءة لطالبات قسم الاقتصاد الإسلامي في جامعة دار السلام كونتور. وإفها تنطوي على ثلاثة عشر موضوعا، نصوصها وتدريباها وبحموعة المفردات المرتبّة حسب الأحرف الهجائية.

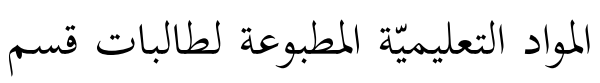
الاقتصاد الإسلامي تحتوي على الموضوعات الآتية: الاقتصاد وتطوّره، والاقتصاد الإسلامي الإسي 
الباحثة على الأهداف المختلفة من المراجع

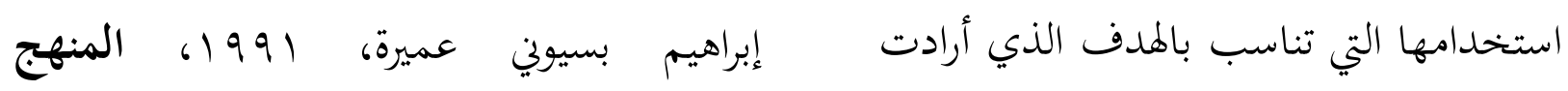

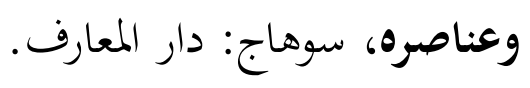$$
\text { أن تحصل عليه الباحثة. }
$$

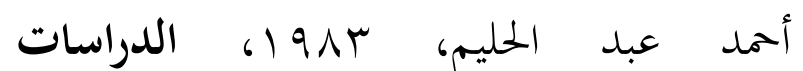

اللغوية:عدد خاص تعليم اللغة العربيّة

لغير الناطقين بها، سودان: بشركة فال

$$
\text { للإعلان والطباعة. }
$$

أحمد فؤاد محمود علهان، بو 199، المهارات

اللغوية: ماهيتها وطرائق تدريسها،

الطبعة الأولى، الرياض: دار المسلم للنشر

$$
\text { والتوزيع. }
$$

رشدي أحمد طعيمة، 919 19، تعليم العربيّة لغير

الناطقين بها: مناهجه وأساليبه،

إيسيسكو: منشورات المنظمة الإسلاميّة

$$
\text { للتربية والعلوم والثقافة. }
$$

رشدي أحمد طعيمة، دون السنة، المرجع في

تعليم اللغة العربيّة للناطقين بلغات

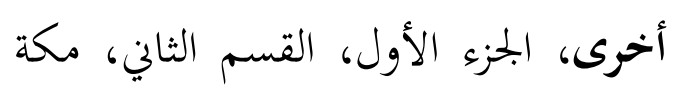



طه على حسين الدليمي وسعاد عبد الكريم

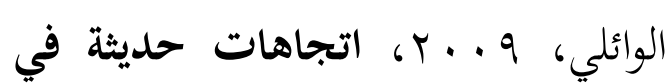

تدريس اللغة العربيّة، الأردن: جدارا

$$
\text { للكتاب العالمي وعالم الكتب الحمديث. }
$$

ץ. فعالية المواد التعليمية لدرس اللغة العربية

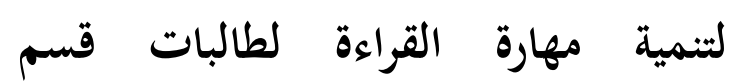
الاقتصاد الإسلامي بجامعة دار السلام كونتور

كما سبق البيان، قامت الباحثة

بتقلديم المواد التعليميّة التي تمّ تصميمها إلى الحبراء، وأها أيضا قامت بالاختبار القبلي والبعدي لطالبات قسم الاقتصاد الإسلامي. اتّضح الفرق بين نتائج الاختبار القبلي ونتائج الاختبار البعدي. فارتقاء تلك النتائج دليل على جذّابة المواد التعليميّة المصممة. وبالإضافة إلى ذلك، أن تحليل نتائج الاختبارين القبلي والبعدي ببرنامج الإصدار 7 1، . يدل على قبول الفرضية

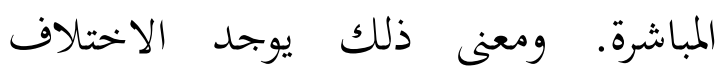
الملحوظ بين معدل نتائج الطالبات في الاختبار القبلي (قبل استخدام المواد التعليميّة) وبينه في الاختبار البعدي (بعد البعدئ

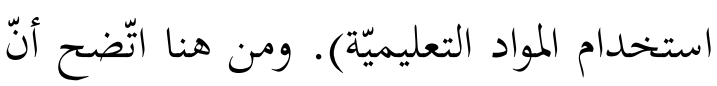

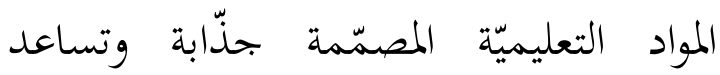
الطالبات في تعلّم درس اللغة العربية لترقية مهارتنّ في القراءة، فهذه هي التي تبيّن مدى فعالية هذه المواد التعليميّة. 
فتحي علي يونس وآخرون، دون السنة، أساسيات تعليم اللغة العربيّة والتربية الدينية، القاهرة: دار الثقافة للطباعة

$$
\text { والنشر. }
$$

قسم المنهج الدراسي، هبع ا، أصول التربية والثعليم، الجزء الثالث، مقرر للصف

الخامس، الطبعة المنقحة الثانية، فونوروكو:

$$
\text { دار السلام للطبعة والنشر. }
$$

لهم الدين، ع ا.با، تدخيل التربية الإسلامية في نصوص القراءة لتعليم اللغة العربيّة،

$$
\text { العدد اله الرقم 1، أبريل. }
$$

محمد صالح سمك، 1919 1، فنّ التدريس للتربية اللغوية وانطباعاتها المسلكية وأنماطها

$$
\text { العملية، القاهرة: دار الفكر العربي. }
$$

محمود كامل الناقة ورشدي أحمد طعيمة، بـ19 1)

الكتاب الأساسي لتعليم اللغة العربيّة

للناطقين بلغات أخرى: إعداده تحليله - تقويمه، مكة المكرّمة: جامعة إسمدين

$$
\text { أم القرى. }
$$

محمود كامل الناقة ورشدي أحمد طعيمة، ب. . . T، طرائق تدريس اللغة العربية لغير الناطقين بها، إيسيسكو: منشورات المنظمة الإسلامية للتربية والعلوم والثقافة. محمود كامل الناقة، 01911، تعليم اللغة العربيّة للناطقين بلغات أخرى: أسسه -
عبد الرحمن بن إبراهيم الفوزان، ^ץـ (، إعداد مواد تعليم اللغة العربيّة لغير الناطقين بها (مختصرات)، مقالة غير منشورة.

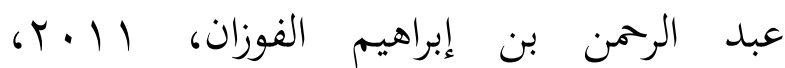
إضاءات لمعلّمي اللغة العربيّة لغير الناطقين بها، الطبعة الأولى، الرياض:

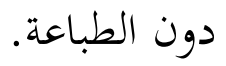

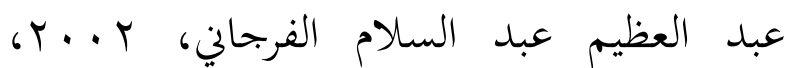
تكنولوجيا إنتاج المواد التعليمية، القاهرة: دار غريب للطباعة والنشر. عبد العليم إبراهيم، ابلو 19، الموجه الفني لمدرسي اللغة العربيّة، القاهرة: دار المعارف.

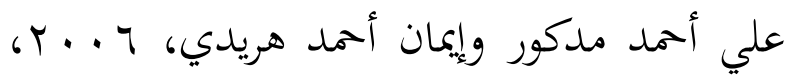
تعليم اللغة العربيّة لغير الناطقين بها: النظرية والنطبيق، القاهرة: دار الفكر

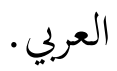
علي أحمد مدكور، 991 1، تدريس فنون اللغة العربيّة، القاهرة: دار الفكر العربيّ. علي إسماعيل محمد، دون السنة، المنهج في اللغة العربيّة، القاهرة: مكتبة وهبة. عمر صديق عبد الله، ^.... ب، تعليم اللغة العربية للناطقين بغيرها: الطرق والأساليب والوسائل، الجيزة: دار العالمية لمنشر والتوزيع. 
هبة محمد عبد الحميد، T . . T، أنثطة ومهارة

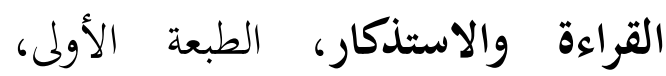

عمان: دار صفاء للنشر والتوزيع.

Sugiyono, 2014, Metode Penelitian Kuantitatif, Kualitatif dan $R \& D$, Cetakan XX, Bandung: Alfabeta.

Pawito, 2007, Penelitian Komunikasi Kualitatif, Yogyakarta: PT. Pelangi Aksara.

Misbahuddin dan Iqbal Hasan, 2003, Analisis Data Penelitian dengan Statistik, Jakarta: Bumi Aksara.

Kathleen F Weaver, et al., 2017, "Basic in SPSS" An Introduction to Statistical Analysis in Research, Hoboken, NJ, USA: John Wiley \& Sons, Inc..
مداخله - طرق تدريسه، مكة المكرمة:


معهد دار السّلام كونتور للتربية الإسلامية الحديثة، ؟ ا.بr، وردون رسالة آخر السنة بثلاث لغات العربيّة والإنجليزية

$$
\text { والإندونيسية، كونتور فونوروكو. }
$$

نايف معروف، 1999 19، خصائص العربية وطرق تدريسها، بيروت: دار النفائس. 